Research Article

\title{
Seismic Analysis of Isolated Continuous Bridge considering Influence of Seawater and Site Condition
}

\author{
Baokui Chen ${ }^{(D)},{ }^{1}$ Yujie Du $\left(\mathbb{D},{ }^{1}\right.$ Yan Shi $\mathbb{D}^{2},{ }^{2}$ and Li Fan ${ }^{1}{ }^{1}$ \\ ${ }^{1}$ School of Civil Engineering and Architecture, Nanchang University, Nanchang 33031, China \\ ${ }^{2}$ School of Civil Engineering, Lanzhou University of Technology, Lanzhou 730050, China \\ Correspondence should be addressed to Yan Shi; syky86@163.com
}

Received 26 May 2021; Accepted 13 August 2021; Published 24 August 2021

Academic Editor: Moon G. Lee

Copyright (C) 2021 Baokui Chen et al. This is an open access article distributed under the Creative Commons Attribution License, which permits unrestricted use, distribution, and reproduction in any medium, provided the original work is properly cited.

The effects of seawater and site conditions on the seismic response of the isolated continuous girder bridge are evaluated in this study. The seawater-muddy soil-isolated bridge coupling model is built in the dynamic analysis software ADINA, and the external seismic wave input is realized by the seismic wave motion analysis program. The influences of seawater and muddy soil on the seismic response of isolated continuous girder bridges are determined by comparing different offshore site models. The results indicated that the seawater and the muddy soil magnify the displacement of the seabed. The existence of seawater increases the longitudinal relative displacement of piers by $20 \%-40 \%$ but has limited influence on the bending moment and shear force of piers. The muddy soil can increase the longitudinal relative displacement and internal force of the piers remarkably. Moreover, the displacement of bridge bearings increases significantly under the combined influence of muddy soil and seawater. In the seawatermuddy soil-isolated bridge coupling model, the seawater and site condition can influence the seismic performance of sea-crossing bridges obviously.

\section{Introduction}

In recent years, the construction of the sea-crossing bridge is in the ascendant. Compared with the onshore bridge, the service environment of the sea-crossing bridge is more complicated. In addition to the effect of the dynamic loads such as wind, wave, and current, the seawater scours and chloride ion corrosion can also influence the seismic performance of sea-crossing bridges. Eastern China is close to the Circum-Pacific seismic belt, and there are often seismic activities in the bridge site, so it is necessary to analyze the seismic performance of sea-crossing bridges with the combined action of multiple factors.

In recent decades, many scholars have studied the dynamic response of bridges under the action of wave and current [1-6]. They found that wave and current could increase the dynamic responses of the internal forces of bridge foundation, elevated pile cap, and displacement of the superstructure. However, only a few studies have been carried out to analyze the dynamic response of sea- crossing bridges subjected to combined earthquake and wave-current actions. Li [7] proposed a method of dynamic response analysis for bridges in deep water under combined actions of earthquake and wave using the linear radiation wave theory and diffraction wave theory. The results indicated the bridge response in deep-water models under separate earthquake and wave actions is nonlinear and cannot be combined by superposition. This conclusion has also been verified by literature [8]. Yuan [9] studied the load effect of bridge piers under combined wave and earthquake actions by the extended Morison equation. The results show that the horizontal force and bending moment of pile block and the maximum bending moment of pile foundation under the wave and seismic action are larger. Ding [10] conducted a stochastic dynamic analysis on response characteristics of deep-water piers in different load cases with earthquake and wave action. Liu [11] drew the conclusion that hydrodynamic pressure can influence the results of bridge responses through numerical simulation and underwater shaking table tests. Ding [12] also 
found that the water layer can enlarge the dynamic responses of piers and decrease the natural frequencies of piers in an underwater shaking table test. Taking the circular pier as the research object, Wang [13] analyzed the seismic response and wave force of the pier under earthquake and wave-current combined action. It was found that the bridge pier displacement is more sensitive to wave force when the seismic load is limited. The wave force can be increased by the wave-current combination action. Jiang [14] and $\mathrm{Wu}[15,16]$ systematically discussed the seismic response characteristics and influence of parameters of the deep-water piers under different wave and current parameters. The results indicated that wave and current can change the seismic response of piers, the extent of which is related to the ground motion spectrum characteristics, as well as the wave and current parameters, especially wave period. The studies of Li [17] and Cheng [18] on chloride ion corrosion showed that the corrosion effect will increase the damage index of the sea-crossing bridge, reduce the maximum value of the pier bottom shear and bending moment, and thus reduce the seismic performance of the bridge. Wang [19] conducted a shaking table test of bridge piers and piles considering the action of scouring. It is found that the pile moment increases with the scoured depth increases whereas the pier moment decreases, and the failure mechanism of the bridge may transfer from piers to piles. Liu [20] conducted a shaking table test of a bridge tower under the combined earthquake and wave-current action. Compared with wave and current, seismic loads have the greatest impact on the seismic response of bridge towers. The acceleration of the tower top is the most sensitive to the earthquake.

Based on the above summary and Liu's experiment [20], it is found that, compared with other factors, seismic action has the most significant influence on the dynamic response of sea-crossing bridges. Compared with the terrestrial environment, there are seawater and seafloor sediment layers in the marine environment, which makes the offshore ground motion greatly different from the onshore ground motion. It is necessary to determine the effects of seawater and site conditions on the seismic response of sea-crossing bridges, which is of great significance to the seismic design of sea-crossing bridges and other marine structures.

Diao [21] determined the influence of the water layer on vertical components of offshore ground motion and analyzed the characteristics of offshore ground motion on the basis of Boore [22]. The results show that the offshore vertical motion is influenced by the water layer, and the softsoil layer can enlarge the long-period component of the horizontal acceleration. Li [23] synthesized offshore ground motions stochastically based on the SWWA seismological model. The results indicated that the vertical component of offshore ground motion was significantly lower than that of onshore ground motion. Dhakal [24] collected the offshore ground motion recorded by the K-NET station in Japan and studied the influence of nonlinear site conditions on the ground motion. It is found that the nonlinear soil layer will decrease the high-frequency components of offshore motions and transfer the peak to lower frequencies. Chen $[25,26]$ analyzed the characteristics of offshore ground motions based on observed strong motion records. The results indicated that the horizontal long-period component of offshore ground motions is more outstanding. The vertical-to-horizontal response spectral ratio of offshore ground motions is lower than that of onshore ground motions in high frequencies. The above studies show that the characteristics of offshore ground motions are obviously different from onshore ground motions.

Sea-crossing bridges are often built on the seabed with a silt soft-soil layer. Therefore, the consideration of soilstructure interaction (SSI) is necessary for the seismic analysis of sea-crossing bridges. Soneji [27] studied the influence of SSI on the seismic response of the Quincy Bay view Bridge. It is found that the soil covering can amply the seismic response of isolated bridges, especially for the bearing displacement. Li [28] used the lumped-parameter (L-P) model to describe the dynamic behavior of SSI for Sutong Cable-stayed Bridge. The results show that the tower displacement was increased and the internal forces of the tower were decreased by the SSI effect. Li [29] performed a seismic fragility analysis of sea-crossing cablestayed bridges considering SSI by the p-y method. It is concluded that SSI is essential in the fragility analysis of sea-crossing bridges, and the numerical results for bridge models with the SSI effect are unsafe. Tochaei [30] analyzed the effect of SSI on bridge response by a shaking table test of a cable-stayed bridge. It was concluded that soft soil can amplify the bridge response. Sun [31] also carried out a shaking table test to evaluate the pile-soil-structure interaction (PSSI) effects on the seismic responses of a longspan cable-stayed bridge model. The results indicated that PSSI effects are related to the frequency contents of inputted earthquake waves. Bi [32] found that the SSI effect cannot be neglected especially for the soft site. The structural response can be increased by the SSI effect for resonating with the local site. This conclusion has also been verified in the literature [33].

It can be found that seawater, soil-structure interaction, and site conditions have an influence on the seismic response of bridges through the summarization of the above researches on the seismic performance of sea-crossing bridges. However, there are few comparative analyses on the seismic performance of sea-crossing bridges considering the influence of seawater and muddy soil layer. This paper takes the continuous isolated bridge, the approach bridge of the Hong Kong-Zhuhai-Macao Bridge as an example. Based on the finite element dynamic analysis software ADINA [34], a numerical model including seawater-muddy soil-isolated bridge is established. The external seismic wave input is realized by the seismic wave analysis program. Taking into account the factors such as seawater, site condition, and soil-structure interaction, the detailed numerical analysis of the sea-crossing bridge is realized. The influence of the seawater layer and muddy soil layer on the sea-crossing isolated bridges is analyzed in detail, which provides a reference for the seismic design of marine structures. 


\section{Numerical Model}

This paper takes a continuous girder bridge, which is the approach bridge of the Hong Kong-Zhuhai-Macao Bridge as an example, as shown in Figure 1. The bridge is a nonnavigable continuous girder bridge in the deep-water area, with a total length of $13.89 \mathrm{~km}$ and a $110 \mathrm{~m}$ equal span layout. The clearance height is $20 \mathrm{~m}$, and the width is $85 \mathrm{~m}$. The working condition defined in the seismic fortification criterion is 120 years, the ultimate state is 600 years, the structural integrity state is 2400 years, and the basic seismic intensity is VII $[35,36]$. The main girder of the bridge is the double-cell and single-box thin-wall steel box girder with a width of $33.1 \mathrm{~m}$ and a height of $4.5 \mathrm{~m}$. Steel tube composite pile is selected for foundation, and 6 foundation piles are used. The thickness of the steel tube is $22 \mathrm{~mm}$ and the steel tube is filled with concrete to make core concrete. Pile caps are prefabricated with a size of $10.6 \mathrm{~m} \times 15.6 \mathrm{~m} \times 5.0 \mathrm{~m}$, and all buried below the seabed surface. The piers are $4.0 \mathrm{~m} \times 10.0 \mathrm{~m}$ prefabricated hollow piers. The high-damping lead rubber bearing is used for this bridge [37].

In consideration of the complexity of the models including the submarine site, seawater layer and sea-crossing bridge, and the huge amount of calculation for seismic wave motion analysis, only a two-dimensional seismic analysis numerical model was established in the study, and equivalent modeling was done for the three-dimensional bridge components.

2.1. Bridge Model. The $Y$ axis, $Z$ axis, and $X$ axis are longitudinal, vertical, and transverse axes of the bridge model, respectively. The degrees of freedom are set to allow horizontal degrees of freedom for the $Y$ and $Z$ axes and rotational degrees of freedom for the $X$ axis. Beam element is used to simulate the main girder, bent cap, pier, pile cap, and pile foundation, considering the dead weight. The material parameters for each component are shown in Table 1 . The bearing used in the bridge is lead rubber isolation bearing, which is simulated by two parallel springs, in which the vertical spring is linear spring and the horizontal spring is nonlinear spring. The bearing hysteresis model uses the Bouc-Wen model. The two-dimensional equivalent model is shown in Figure 2.

2.2. Submarine Site Model. Combined with the relatively flat topography and relatively simple geological conditions in the Lingdingyang Bay [38, 39], a flat submarine site model was established, including seawater layer, muddy soil layer, clay soil layer, sand soil layer, strongly weathered granite layer, and weakly weathered granite layer. The parameters of overburden layers [40] are shown in Table 2.

According to Yang's theory [41], the unsaturated bidirectional dielectric soil considering porosity and saturation was transformed into an equivalent linear elastic medium for simplified simulation of muddy soil. The specific derivation process is as follows: Yang and Sato [42] give a formula for the calculation of $\mathrm{P}$-wave and SV-wave velocities under the influence of pore water and saturation contained in the soil layer.

$$
\begin{aligned}
& v_{p}=\sqrt{\frac{\lambda+2 G+\alpha^{2} M}{\rho}}=\sqrt{\frac{\left(G\left(2-2 \mu^{\prime}\right) / 1-2 \mu^{\prime}\right)+\alpha^{2} M}{\rho}}, \\
& v_{s}=\sqrt{\frac{G}{\rho}}
\end{aligned}
$$

where $\rho$ is the true density of the soil layer $\rho=(1-n) \rho_{s}+n \rho_{f} ; \rho_{s}$ and $\rho_{f}$ are the density of soil particles and pore water, respectively; $G$ is the shear modulus of soil layer; $\mu^{\prime}$ represent Poisson's ratio of soil skeleton.

$$
\mu^{\prime}=\frac{\lambda}{2(\lambda+G)} .
$$

Moreover, $\alpha$ and $M$ are defined to represent soil particle and water compression performance respectively, which can be obtained through the following equations.

$$
\begin{gathered}
\alpha=1-\frac{K_{b}}{K_{s},} \\
M=\frac{K_{s}^{2}}{K_{d}-K_{b}},
\end{gathered}
$$

where $K_{s}$ and $K_{b}$ are the elastic modulus of soil particles and soil skeleton, respectively; $K_{d}$ is the conversion parameter.

Equations (1) and (2) can be used to derive the true Poisson's ratio of the soil layer considering pore water.

$$
\mu=\frac{1}{2}\left(1-\frac{G}{\lambda+\alpha^{2} M+G}\right) .
$$
form:

Taking (3) into equation (6), we get the following

$$
M=\frac{1}{2} \frac{\left(2 \mu^{\prime} /\left(1-2 \mu^{\prime}\right)\right)+\left(\alpha^{2} M / G\right)}{\left(1 /\left(1-2 \mu^{\prime}\right)\right)+\left(\alpha^{2} M / G\right)} .
$$

From the above, the P-wave velocity, SV-wave velocity, and Poisson's ratio of the soil layer considering pore water and saturation can be calculated from equations (1)-(7), and these parameters conform to the basic relationship of linear elastic materials.

The submarine site model including seawater and various soil layers is built by the computational fluid dynamics (CFD) program in ADINA software. The total length of the submarine site is $860 \mathrm{~m}$. The water depth is $10 \mathrm{~m}$ in the model, and the total depth of the five overburden layers is $105 \mathrm{~m}$. The thickness of each soil layer is muddy soil layer $(15 \mathrm{~m})$, clay soil layer $(20 \mathrm{~m}$ or $35 \mathrm{~m})$, sand soil layer $(20 \mathrm{~m})$, strongly weathered granite layer $(20 \mathrm{~m})$, and weakly weathered granite layer $(30 \mathrm{~m})$. The seawater is regarded as a potential fluid and simulated by a $2 \mathrm{D}$ fluid element. The soil layer is regarded as isotropic linear elasticity material and simulated by the $2 \mathrm{D}$ solid element, considering that the outof-plane thickness is $18 \mathrm{~m}$. In order to understand the influence of seawater layer and muddy soil layer on offshore 


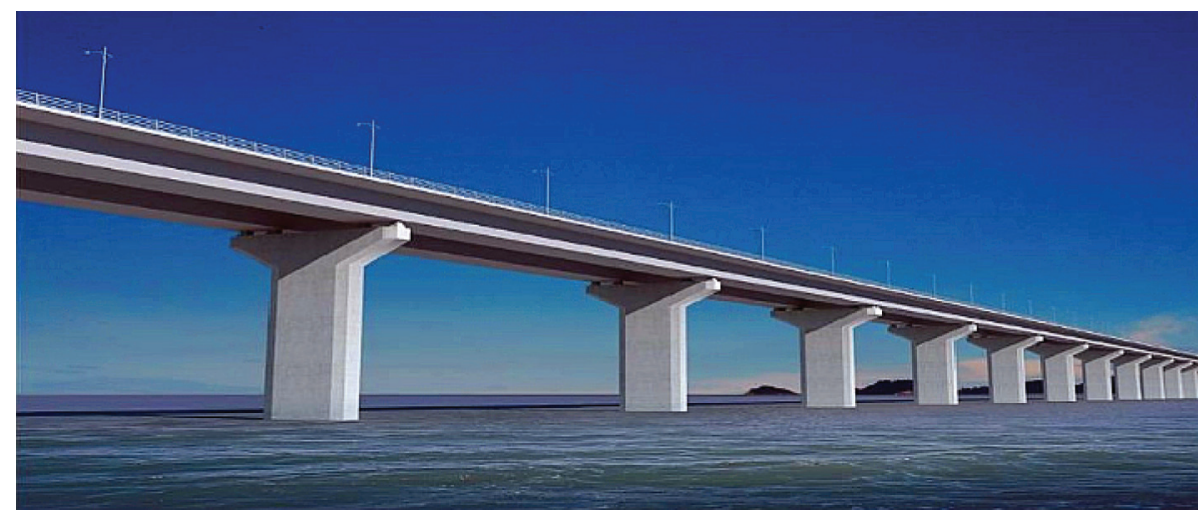

Figure 1: Diagram of nonnavigable continuous girder bridge of Hong Kong-Zhuhai-Macao Bridge.

TABLE 1: Material parameters of components.

\begin{tabular}{|c|c|c|c|c|}
\hline Component & Material & Density $\left(\mathrm{kg} / \mathrm{m}^{3}\right)$ & Poisson's ratio & Elastic modulus (MPa) \\
\hline Main beam & Steel & 7849.5 & 0.3 & 206,000 \\
\hline Bent cap & C50 concrete & 2549.3 & 0.2 & 34,500 \\
\hline Pier & C50 concrete & 2549.3 & 0.2 & 34,500 \\
\hline Pile cap & C45 concrete & 2549.3 & 0.2 & 33,500 \\
\hline \multirow{2}{*}{ Pile foundation } & Q345 steel & 7849.3 & 0.3 & 206,000 \\
\hline & C40 concrete & 2549.3 & 0.2 & 32,500 \\
\hline
\end{tabular}



Figure 2: Equivalent schematic diagram of lead rubber bearing.

TABLE 2: Material parameters of submarine site overburden layer.

\begin{tabular}{lcccccc}
\hline Soil type & $\begin{array}{c}\text { Density } \\
\rho\left(\mathrm{kg} / \mathrm{m}^{3}\right)\end{array}$ & $\begin{array}{c}\text { Shear velocity } \\
v_{s}(\mathrm{~m} / \mathrm{s})\end{array}$ & $\begin{array}{c}\text { Compression velocity } \\
v_{p}(\mathrm{~m} / \mathrm{s})\end{array}$ & $\begin{array}{c}\text { Poisson ratio } \\
\mu\end{array}$ & $\begin{array}{c}\text { Elastic modulus } \\
E(\mathrm{MPa})\end{array}$ & $\begin{array}{c}\text { Shear modulus } \\
G(\mathrm{MPa})\end{array}$ \\
\hline Seawater & 1000 & - & 1500 & 0.330 & 2340 & - \\
Muddy soil & 1400 & 107 & 1460 & 0.497 & 48 & 16 \\
Clay soil & 1650 & 218 & 1650 & 0.491 & 234 & 78 \\
Sand soil & 1800 & 264 & 1697 & 0.487 & 373 & 125 \\
Strong weathered granite & 2100 & 485 & 2135 & 0.473 & 0.330 & 32700 \\
Weak weathered granite & 2600 & 2175 & 4318 & & 494 \\
\hline
\end{tabular}

ground motion and bridge structure, three types of models were established. The total thickness $(105 \mathrm{~m})$ and total length $(860 \mathrm{~m})$ of the overburden soil layer at all site conditions remained unchanged. By changing seawater layer, muddy soil layer, and clay soil layer, the land site model without muddy soil (Case 1), submarine site model without muddy soil (Case 2), and submarine site model with muddy soil (Case 3 ) were built, as shown in Figure 3.
In the site model containing the seawater layer, the FluidStructure Interaction (FSI) boundary was set between the seawater layer and the overburden soil layer in the calculation process processed by direct coupling. A Free Surface boundary is added to the surface of the seawater layer, and a Fluid-Infinite Region boundary is built on the left and right sides to consider the absorption of the scattered wave by the seawater layer. The effect of foundation radiation damping is 


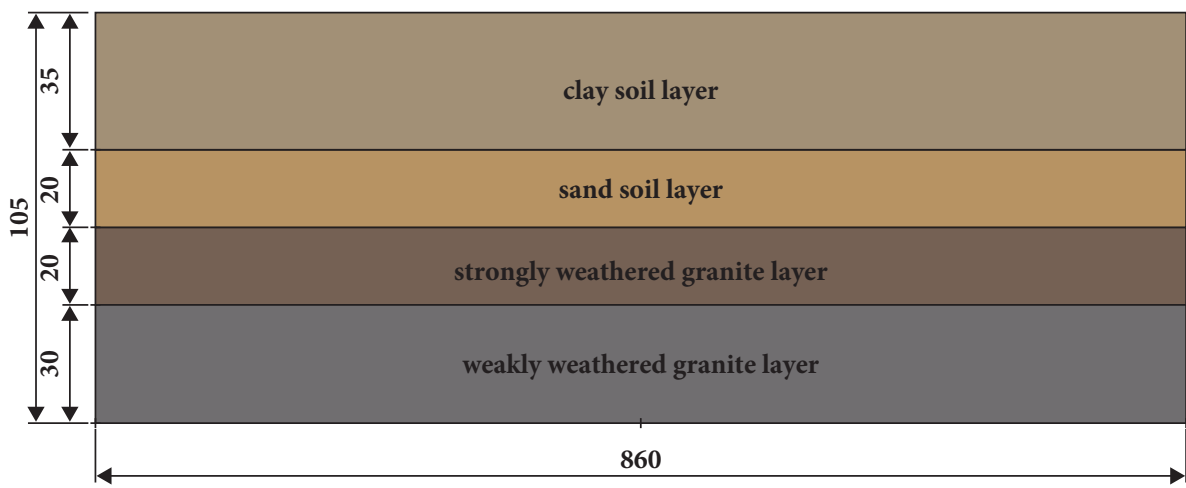

(a)

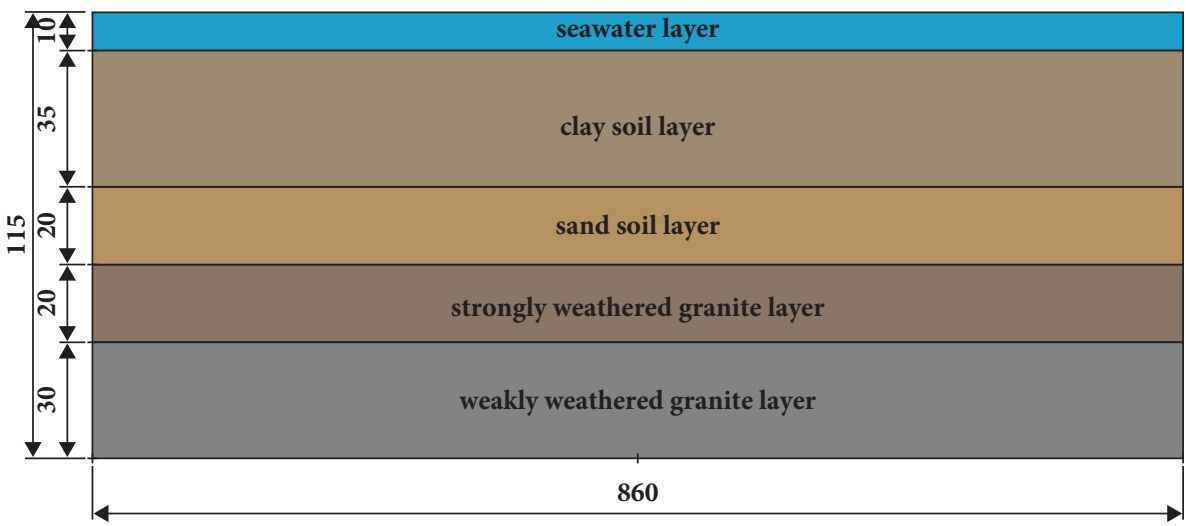

(b)

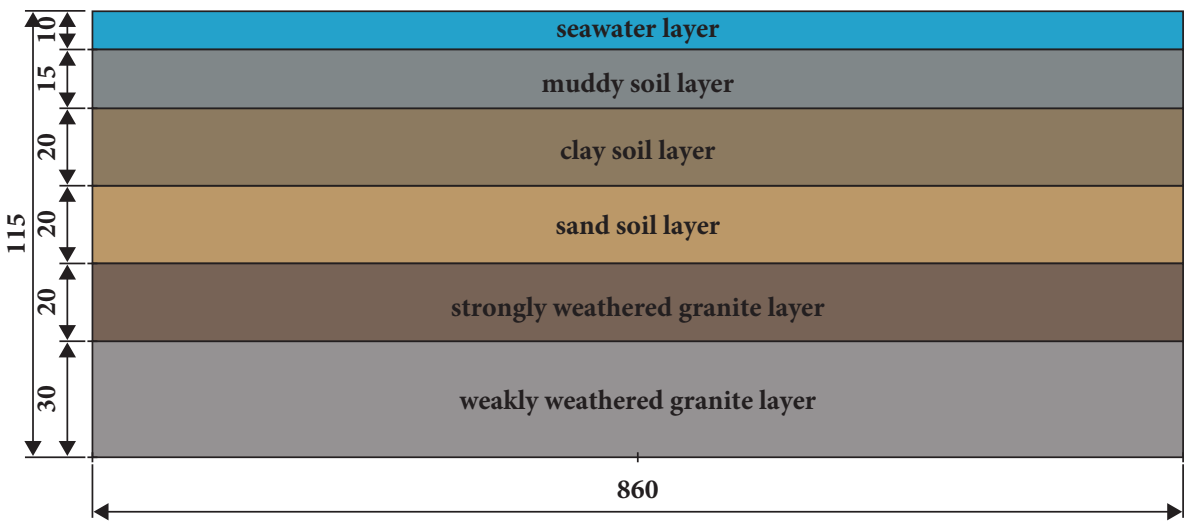

(c)

Figure 3: Schematic diagram of site model (unit: m). (a) Case 1: land site model without muddy soil. (b) Case 2: submarine site model without muddy soil. (c) Case 3: submarine site model with muddy soil.

considered by setting the viscous-spring artificial boundary at the lateral and bottom sides of the overburden soil. The spring element is used in the finite element software ADINA to simulate viscous-spring artificial boundary, and the stiffness and damping coefficient of the spring are calculated by the formula proposed by Liu [43, 44], as follows:

$$
\begin{cases}K_{N}=\alpha_{N} \frac{G}{r} A, & C_{N}=\rho v_{P} A, \\ K_{T}=\alpha_{T} \frac{G}{r} A, & C_{T}=\rho v_{s} A,\end{cases}
$$

where $K_{N}$ and $K_{T}$ are normal and tangential stiffness coefficients, respectively. $C_{N}$ and $C_{T}$ are normal and tangential damping coefficients, respectively. $G$ is the shear modulus of the soil. $v_{s}$ and $\nu_{P}$ are $\mathrm{S}$-wave and $\mathrm{P}$-wave velocity, respectively. $\rho$ is density. $r$ is the distance from the wave source to the artificial boundary. $\alpha_{N}$ and $\alpha_{T}$ are the correction parameters of normal and tangential artificial boundaries, respectively. $\alpha_{N}=1.0$, and $\alpha_{T}=0.5$ in this paper [45]. A represents the effective area corresponding to the node [46], taking into account the out-of-plane thickness. The pile foundation and pile caps are connected with the seawater and the soil by Rigid Links via nodes to simulate 
the coupling effect between the structure and the site, and the subordinate relationship is set up. In the soil layer, the site nodes are the master node and the bridge nodes are the slave node according to the actual stress condition. In the seawater layer, the bridge nodes are used as the master node and the seawater layer nodes as the slave node, to simulate the coupling between the structure and the site. In order to compare the influence of different site factors on the structure of sea-crossing bridges more effectively, a coupling model of seawater layer, submarine site, and sea-crossing bridge considering three types of sites was established in this paper. We keep the bridge structure unchanged, change the seawater layer and the muddy soil layer, and conduct the wave analysis. The numerical model is shown in Figure 4. From left to right, the members of the bridge structure are numbered, and piers 1-7 and spans 1-6 are defined, as shown in Figure 5.

2.3. Ground Motion Selection. Seismic events used in the study are all from Japan's Kik-NET strong ground motion network, and the selected seismic events must be the strong motion records collected by the station on the bedrock and near shore. The selected strong motion records are inputted to different models by means of external wave input. After seismic wave analysis, the response of seabed position is the ground motion which reflects the characteristics of the seawater layer and site conditions. The seismic events of 2011-03-11, 2012-03-14, and 2019-06-18 are used in this study. The information of these three earthquakes was recorded in detail by three stations at the bedrock position, as shown in Table 3.

In this paper, the seismic load input is realized by setting a viscous-spring artificial boundary at the lateral and bottom sides of the overburden soil. The acceleration time history data of three seismic records are modulated according to the seismic fortification criterion of actual engineering to make sure that the PGA is 190 gal. Then, the data after amplitude modulation is used to calculate the displacement time history, and the displacement time history data is inputted into the self-programmed program to calculate the seismic load and then inputted to the nodes on the viscous-spring artificial boundary. The acceleration time history and displacement time history curves of the three horizontal seismic records used are shown in Figures 6-8. In the actual analysis, $80 \mathrm{~s}$ of each seismic record was intercepted for calculation.

\section{Numerical Results}

The numerical results mainly focus on the seismic response of the longitudinal bridge. In order to represent the bridge response accurately, the results of the seismic response calculation of the middle 4 spans are mainly extracted for discussion. By comparing and analyzing the seismic responses of the surface (or seafloor) and the key parts of the isolated continuous girder bridge under three earthquakes, the effects of seawater and muddy soil on the offshore ground motion and the seismic performance of the bridge structure are determined.
3.1. Site Response. The comparison of the displacement time history of the center point of the seabed or the surface (top of the soil layer) during three earthquakes is shown in Figures 9(a)-9(c). The peak value of surface (or seabed) displacement is shown in Table 4. In the events of 2011-03-11 and 2019-06-18, the peak value of the horizontal displacement (PGD) of the submarine site model (Case 2) was significantly larger than that of the land model (Case 1), as shown in Figures 9(a) and 9(c), respectively. In particular, the peak value of surface displacement in Case 2 is more than twice that of Case 1 in the 2011-03-11 earthquake event, as listed in Table 4. In the 2012-03-14 earthquake, there is no significant difference in the peak horizontal displacement between Case 1 and Case 2. However, it can be seen from Figure 9(b) that the overall displacement response of Case 2 is greater than that of Case 1, which indicated that the seawater can amplify the displacement response of the surface or seabed. Similarly, in the 2012-03-14 and 2019-0618 earthquakes, the displacement response of the submarine site model with muddy soil (Case 3) was more intense, with larger amplitude compared to Case 2, and the peak displacement was increased by $33 \%$ and $30 \%$, respectively, due to the presence of muddy soil, as shown in Table 4 . It can be concluded from Figure 9 that the seismic response of Case 3 is generally greater than that of Case 2 under the action of three earthquakes, which indicates that the muddy soil can also enlarge the displacement response of the seabed or surface. In three seismic events, the displacement of the seabed or surface in Case 3 is greater than that in Case 1. In the event of 2011-03-11, the maximum displacement of Case 1 was about $0.10 \mathrm{~m}$, while the maximum displacement of Case 3 reached $0.24 \mathrm{~m}$, as shown in Table 4. It indicated that the amplification effect of surface displacement is more obvious under the combination of muddy soil and seawater.

The acceleration amplification coefficient spectrum of the seabed (or the surface) during the three earthquakes is shown in Figure 10(a)-10(c). As can be seen from the figure, the seawater has no influence on the surface acceleration, because the external seismic wave input adopts the normal incidence of SV wave, while the muddy soil has a significant amplifying effect on the acceleration. Under the action of three earthquakes, the seabed acceleration of Case 3 was magnified by $50 \%, 95 \%$, and $80 \%$, respectively, compared with that of Case 2. The seismic response of seabed indicates that the muddy soil layer can amplify the horizontal acceleration of offshore ground motions. The result is consistent with the characteristics of onshore ground motion with soft soil. Table 4 shows the peak acceleration (PGA) of the seabed or surface in the three earthquakes.

\subsection{Bridge Response}

3.2.1. Relative Displacement of Piers. Table 5 lists the maximum value of relative displacement of all piers in the three earthquakes. Due to limited space, the time history curve of relative displacement of piers is only shown by taking No. 3 pier as an example, as illustrated in Figures 11(a)-11(c). By comparing the longitudinal relative 


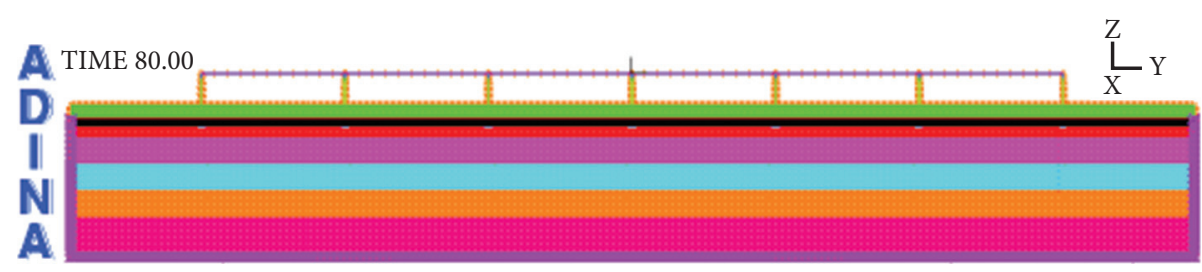

FIgURE 4: Numerical model.

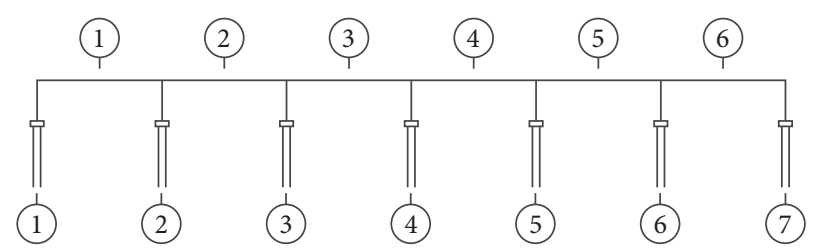

FIGURE 5: Schematic diagram of component number.

TABLE 3: Seismic records information.

\begin{tabular}{lcccccc}
\hline Seismic event & Time & Magnitude $\left(M_{W}\right)$ & Focal depth $(\mathrm{km})$ & Station & Bedrock PGA(gal) & Surface PGA $($ gal $)$ \\
\hline 20110311 & $14: 46: 00$ & 9.0 & 24 & FKSH20 & 356.436 & 660.456 \\
20120314 & $21: 05: 00$ & 6.1 & 15 & CHBH14 & 62.303 & 187.184 \\
20190618 & $22: 22: 00$ & 6.7 & 14 & NIGH02 & 104.631 & 164.226 \\
\hline
\end{tabular}

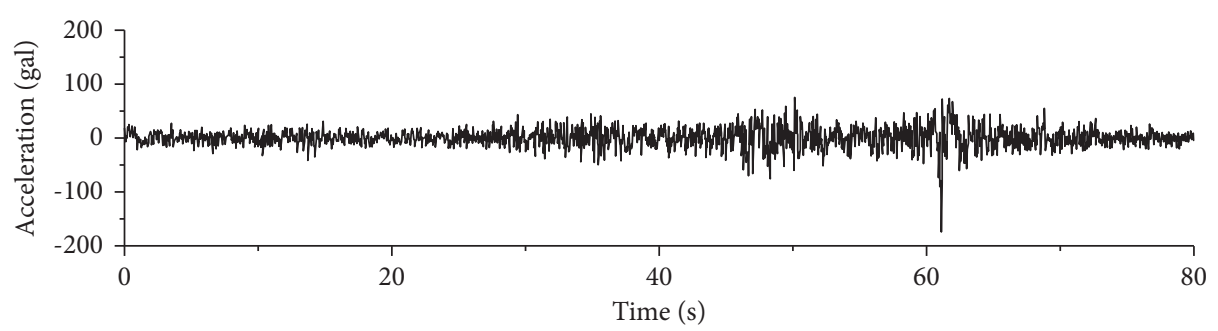

— 20110311 earthquake FKSH20 station

(a)

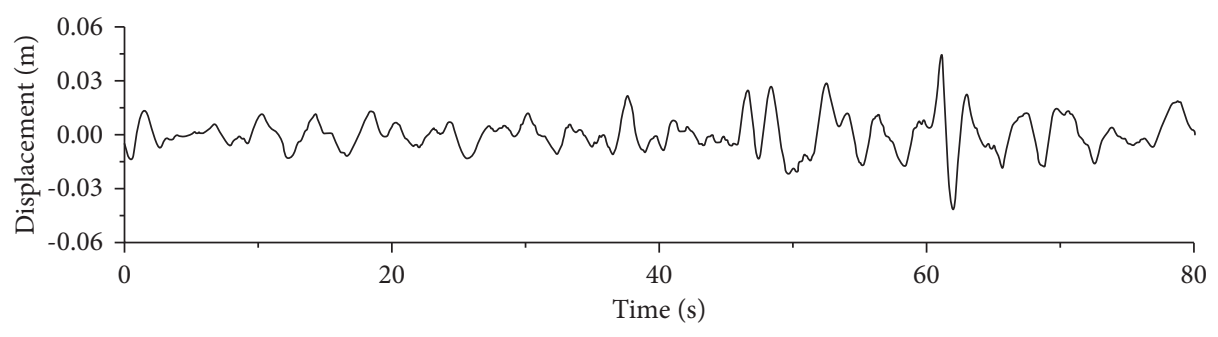

20110311 earthquake FKSH20 station

(b)

FIGURE 6: 2011-03-11 Earthquake time history curve at bedrock in the direction of EW-1 at FKSH20 station. (a) Acceleration time history. (b) Displacement time history.

displacement of No. 3 pier in the submarine model (Case 2) with that in the land model (Case 1), it is found that the structural response of Case 2 is greater in the three earthquakes, as shown in Table 5. In the 2011-03-11 earthquake, the peak value of the relative displacement of No. 3 pier in Case 2 increased by $40 \%$, and the relative displacement of other bridge piers increased by more than $20 \%$ compared with Case 1. In the 2012-03-14 earthquake, the relative displacement of piers in Case 2 increased by $5 \%-20 \%$ compared with Case 1, while the relative displacement increased by more than $20 \%$ in the 2019-06-18 earthquake. In conclusion, seawater has an amplification effect on pier displacement. Moreover, the amplification effect of muddy soil is more obvious (comparison of Case 2 and Case 3). In 


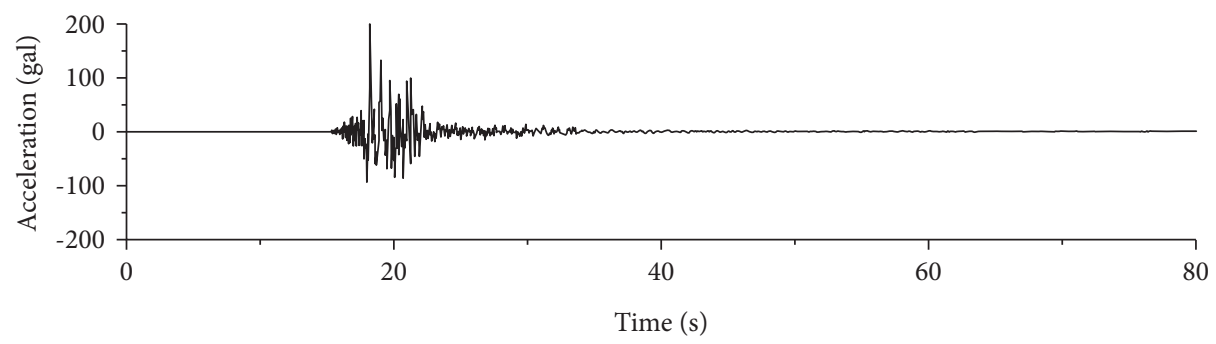

— 20120314 earthquake CHBH14 station

(a)

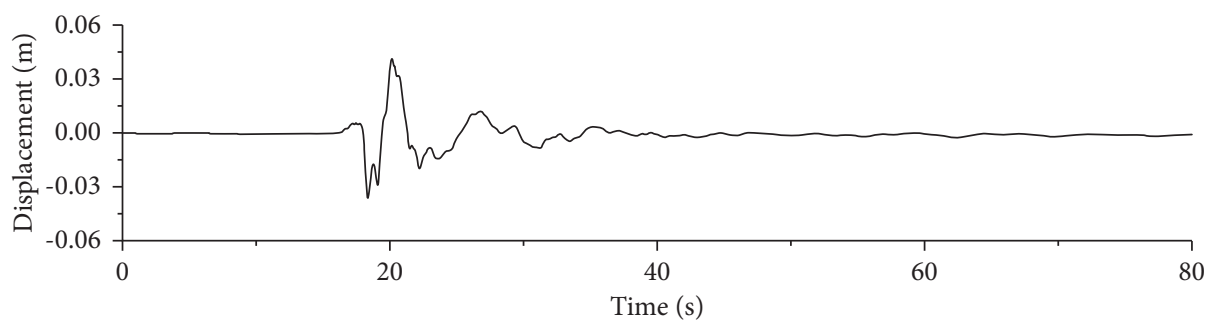

—_ 20120314 earthquake CHBH14 station

(b)

FIGURE 7: 2012-03-14 Earthquake time history curve at bedrock in the direction of EW-1 at CHBH14 station. (a) Acceleration time history. (b) Displacement time history.

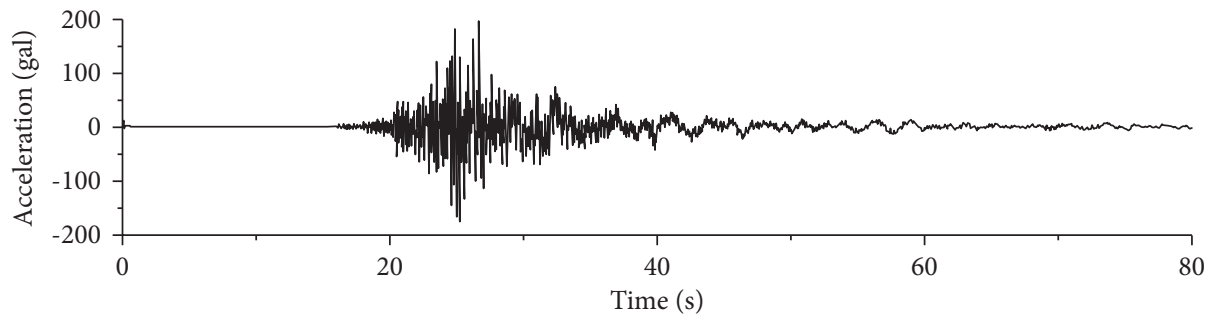

— 20190618 earthquake NIGH02 station

(a)

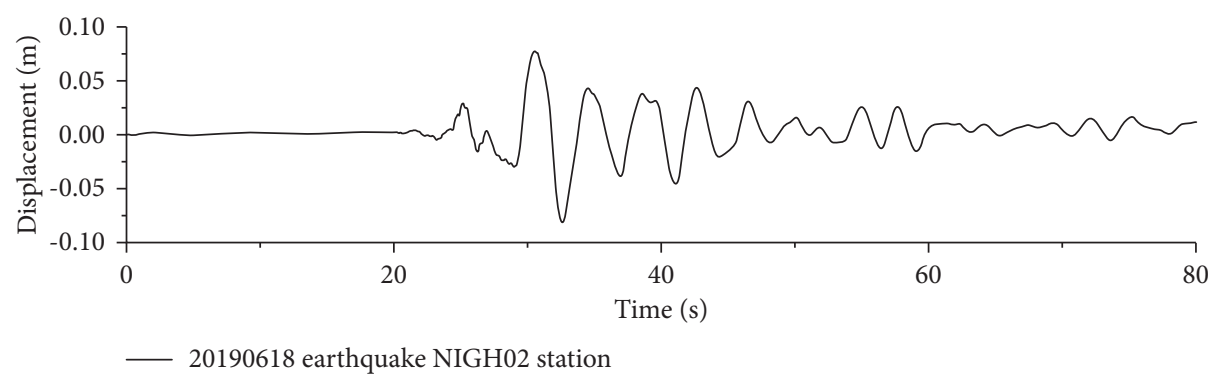

(b)

FIGURE 8: 2019-06-18 Earthquake time history curve at bedrock in the direction of EW-1 at NIGH02 station. (a) Acceleration time history. (b) Displacement time history.

the 2012-03-14 earthquake, the max relative displacement of bridge piers in Case 3 generally increased by more than $50 \%$, up to $80 \%$ at most compared with Case 2, as shown in Table 5. In the other two seismic events, the relative displacement of piers increased by about 30\% due to muddy soil. Under the combined effect of seawater layer and muddy soil, the relative displacement of bridge piers generally increased by more than $80 \%$, and the maximum increase is 1 time. Thus, it can be observed that the muddy soil in the submarine site significantly increases the seismic response of the bridge, and its influence can not be ignored in the seismic design of the sea-crossing bridge. 


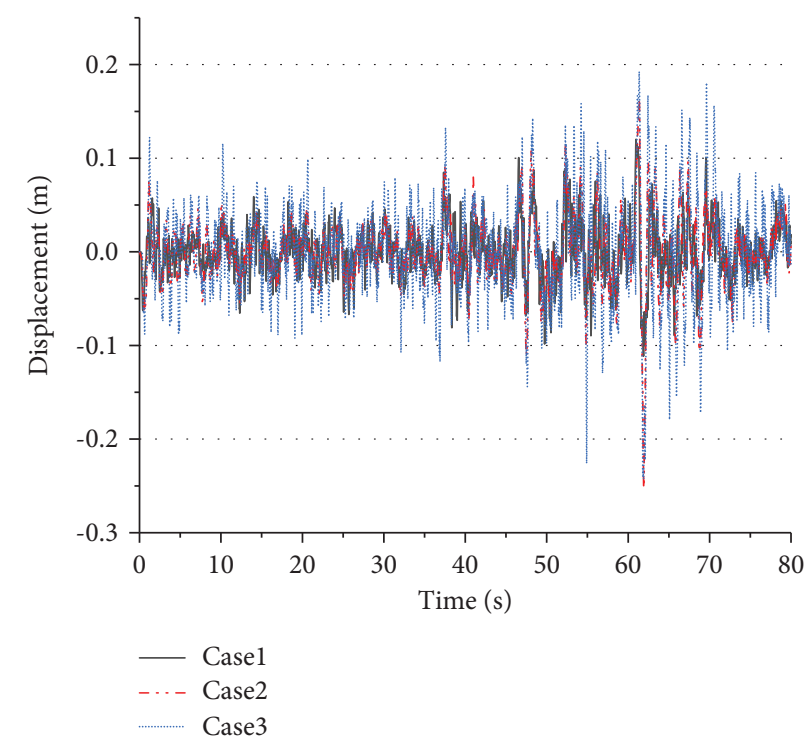

(a)

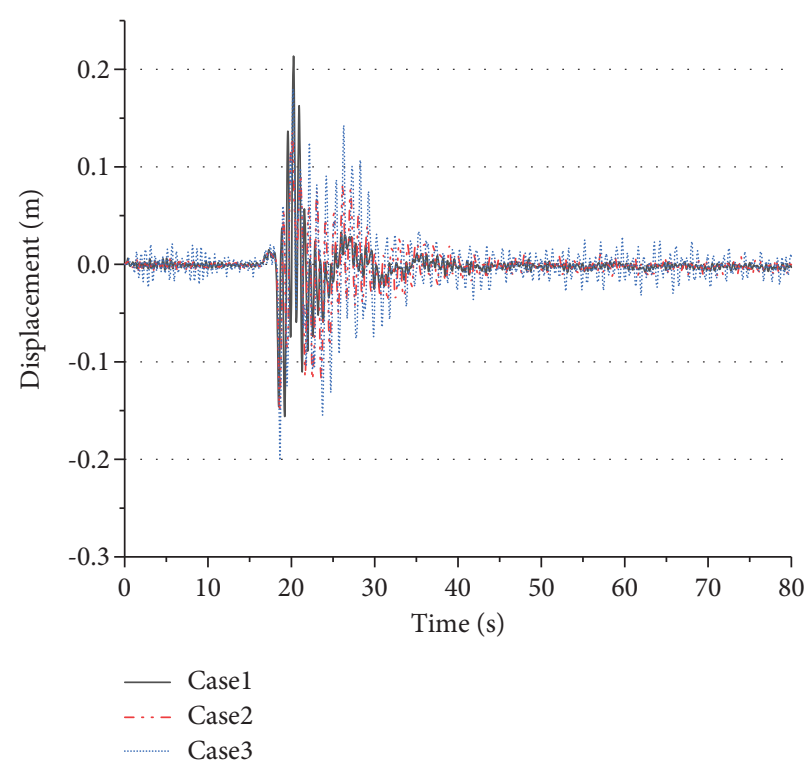

(b)

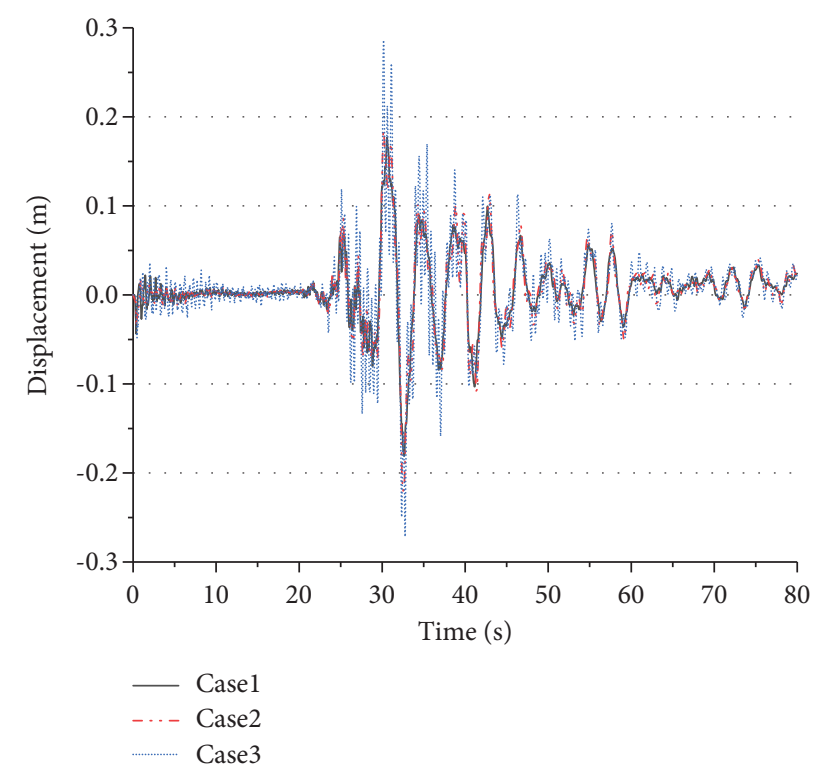

(c)

FIGURE 9: Horizontal displacement time history of the seabed or surface in the three earthquakes. (a) 2011-03-11. (b) 2012-03-14. (c) 201906-18.

TAвLE 4: Peak acceleration and peak displacement of seabed or surface.

\begin{tabular}{|c|c|c|c|c|c|c|}
\hline \multirow{2}{*}{ Earthquake event } & \multicolumn{3}{|c|}{ PGA $\left(\mathrm{cm} / \mathrm{s}^{2}\right)$} & \multicolumn{3}{|c|}{ PGD (m) } \\
\hline & Case 1 & Case 2 & Case 3 & Case 1 & Case 2 & Case 3 \\
\hline 2011-03-11 & 369.737 & 333.254 & 494.501 & 0.120 & 0.253 & 0.243 \\
\hline 2012-03-14 & 11.810 & 13.744 & 26.873 & 0.214 & 0.151 & 0.201 \\
\hline 2019-06-18 & 43.673 & 42.584 & 78.494 & 0.181 & 0.221 & 0.286 \\
\hline
\end{tabular}

3.2.2. Bending Moment and Shear Force. Time history curves of bending moment and shear force at pier bottom are shown in Figures 12 and 13 separately. Due to the limitation of space, pier No. 3 is taken as an example. Tables 6 and 7, respectively, show the peak bending moment and shear force at the pier bottom in the three earthquakes. It can be seen from Figures 12 and 13 that the seawater has little influence on the bending moment and shear force at the pier bottom. In the 2019-06-18 earthquake event, the bending moment and shear force at the pier bottom in the 


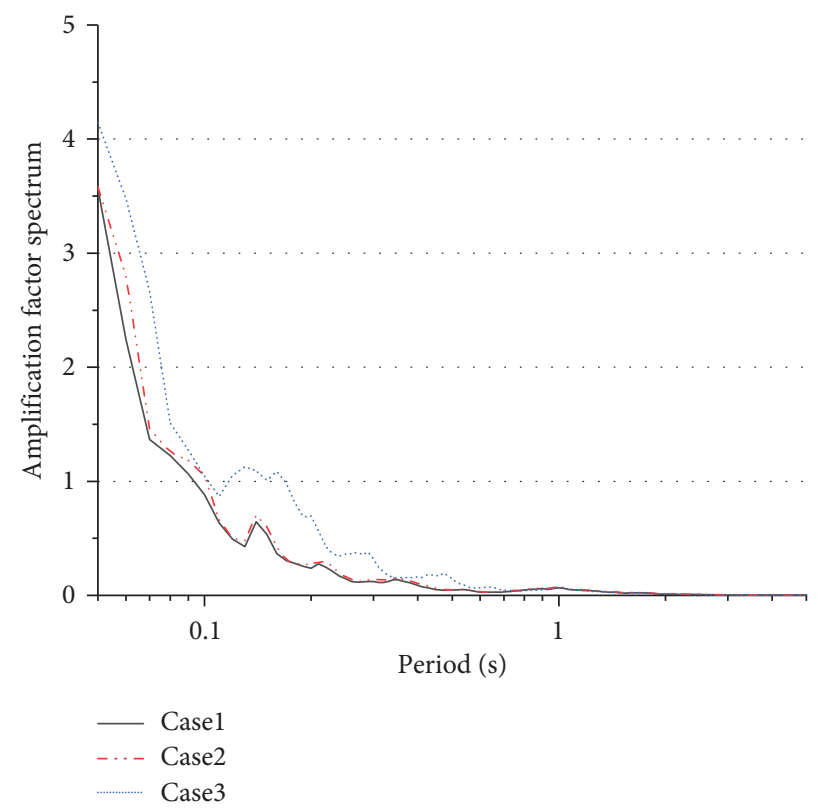

(a)



(b)



(c)

Figure 10: Acceleration amplification factor spectrum of the seabed or surface in the three earthquakes. (a) 2011-03-11. (b) 2012-03-14. (c) 2019-06-18.

TABle 5: Maximum longitudinal relative displacement of piers.

\begin{tabular}{|c|c|c|c|c|}
\hline \multirow{2}{*}{ Earthquake event } & \multirow{2}{*}{ Pier number } & \multicolumn{3}{|c|}{ Maximum displacement of piers (m) } \\
\hline & & Case 1 & Case 2 & Case 3 \\
\hline \multirow{5}{*}{ 2011-03-11 } & 2 & 0.144 & 0.187 & 0.266 \\
\hline & 3 & 0.121 & 0.173 & 0.239 \\
\hline & 4 & 0.146 & 0.188 & 0.300 \\
\hline & 5 & 0.176 & 0.214 & 0.208 \\
\hline & 6 & 0.173 & 0.201 & 0.276 \\
\hline
\end{tabular}


TABle 5: Continued.

\begin{tabular}{|c|c|c|c|c|}
\hline \multirow{2}{*}{ Earthquake event } & \multirow{2}{*}{ Pier number } & \multicolumn{3}{|c|}{ Maximum displacement of piers (m) } \\
\hline & & Case 1 & Case 2 & Case 3 \\
\hline \multirow{5}{*}{ 2012-03-14 } & 2 & 0.167 & 0.181 & 0.320 \\
\hline & 3 & 0.156 & 0.184 & 0.276 \\
\hline & 4 & 0.153 & 0.175 & 0.300 \\
\hline & 5 & 0.162 & 0.170 & 0.293 \\
\hline & 6 & 0.164 & 0.175 & 0.320 \\
\hline \multirow{5}{*}{ 2019-06-18 } & 2 & 0.158 & 0.204 & 0.282 \\
\hline & 3 & 0.182 & 0.232 & 0.301 \\
\hline & 4 & 0.178 & 0.222 & 0.298 \\
\hline & 5 & 0.186 & 0.236 & 0.296 \\
\hline & 6 & 0.175 & 0.210 & 0.291 \\
\hline
\end{tabular}



(a)

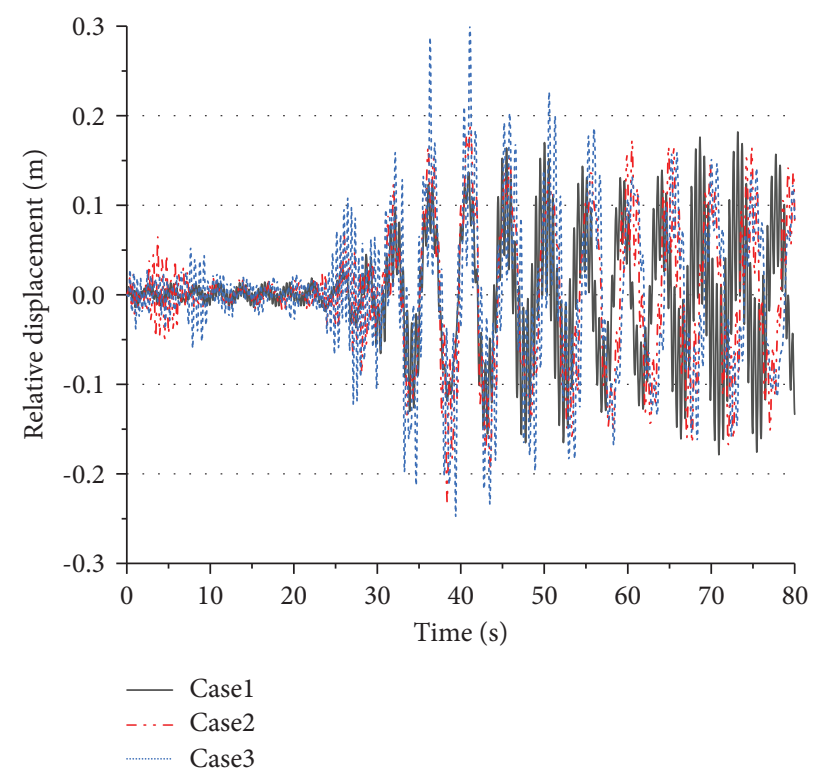

(c)

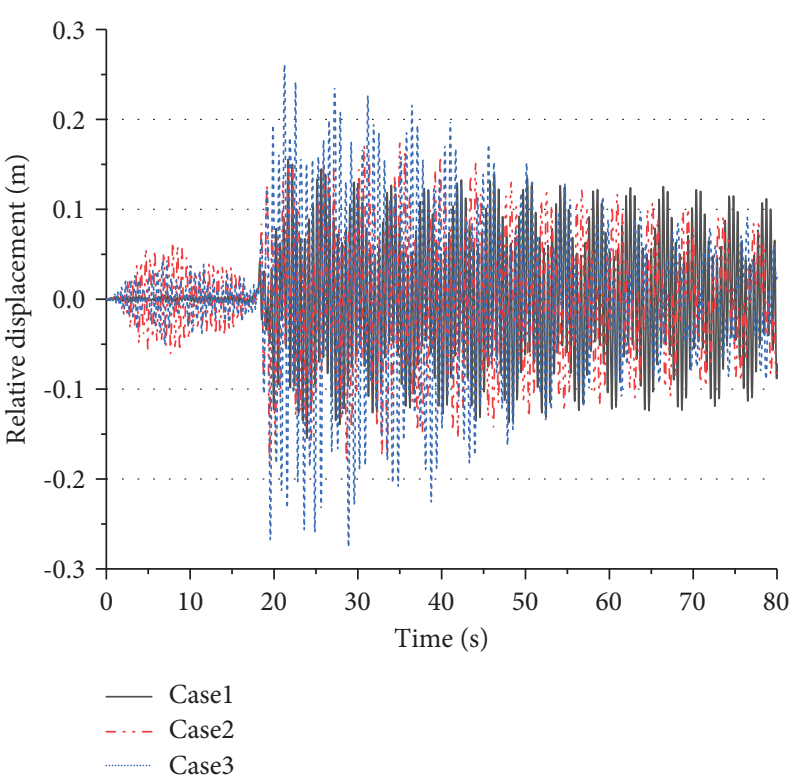

(b) 

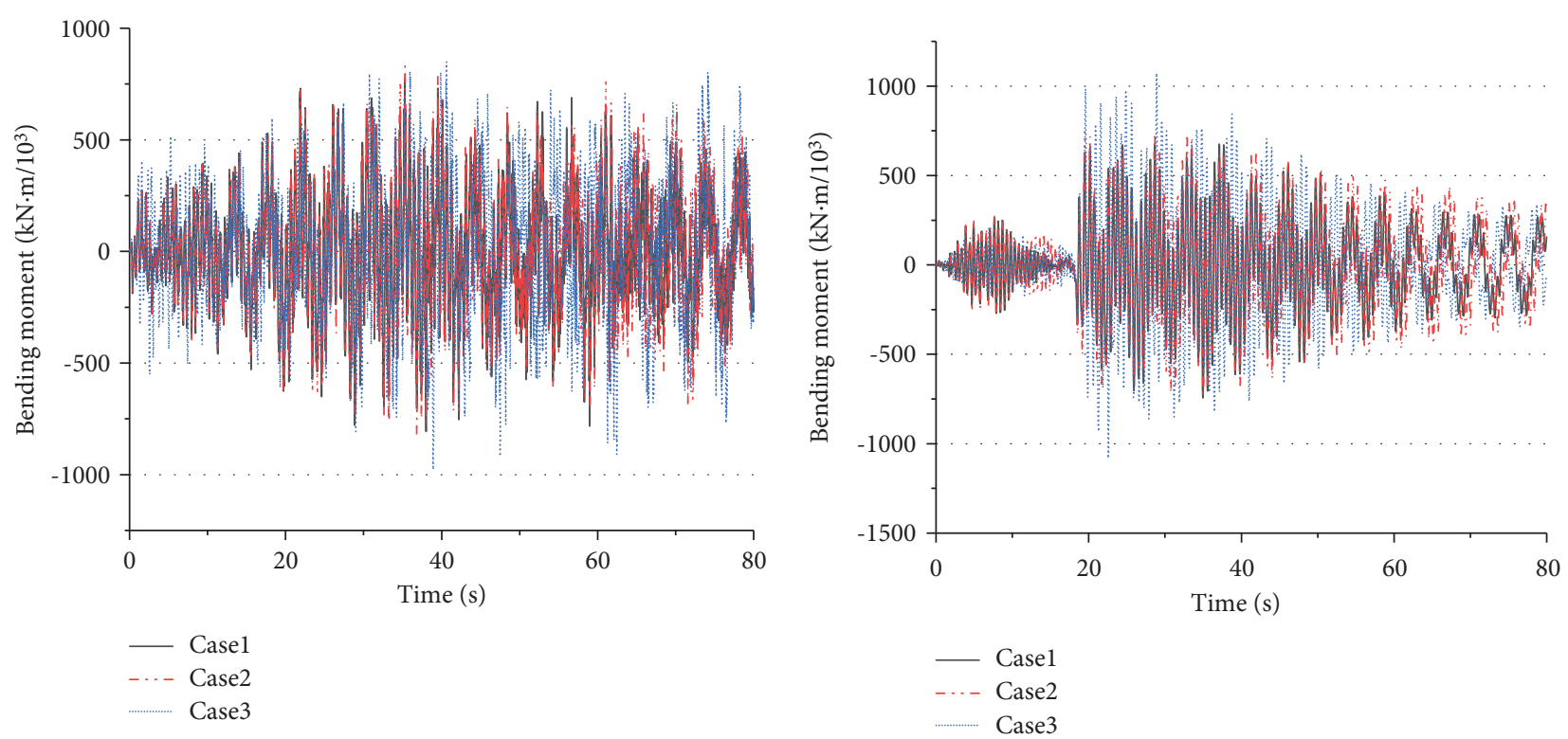

(a)

(b)



(c)

Figure 12: Bending moment time history of No. 3 pier in the three earthquakes. (a) 2011-03-11. (b) 2012-03-14. (c) 2019-06-18.

submarine site model without muddy soil (Case 2) and the land site model (Case 1) are almost equal, as shown in Figures 12(c) and 13(c), respectively. In the other two earthquakes, the bending moment increased by less than $6 \%$ (as listed in Table 6) and the shearing force increased by less than $7 \%$ (as listed in Table 7) due to the presence of seawater. However, the existence of muddy soil significantly increases the bending moment and shear force at the bottom of the piers. In the three earthquakes, the bending moment at the pier bottom of Case 3 is 1.2-1.7 times that of Case 2. Besides, the shear force at the pier bottom is increased by approximately $100 \%-200 \%$ in the 2012-03-14 and 2019-06-18 earthquake events, as shown in Table 7 . Under the combined effect of seawater and muddy soil, the shear force of bridge piers in Case 3 generally increased by more than $20 \%$ compared with Case 1 in the 2011-03-11 earthquake, and the shear force in Case 3 is 1.1-1.6 times than that of Case 1 in the other two earthquakes, as listed in Table 7. Similarly, the bending moment of bridge piers in Case 3 generally increased by $20 \%-70 \%$ compared with Case 1 in three earthquakes, as shown in Table 6 . The bending moment increased by more than one time at most in the 2012-03-14 earthquake, which may change the elastic state of the bridge pier into a plastic state, while the design of a long-span bridge pier should keep the elastic state. Therefore, special attention should be paid to the amplification effect of muddy soil on the bending moment and shear force of bridge piers in the seismic design. 


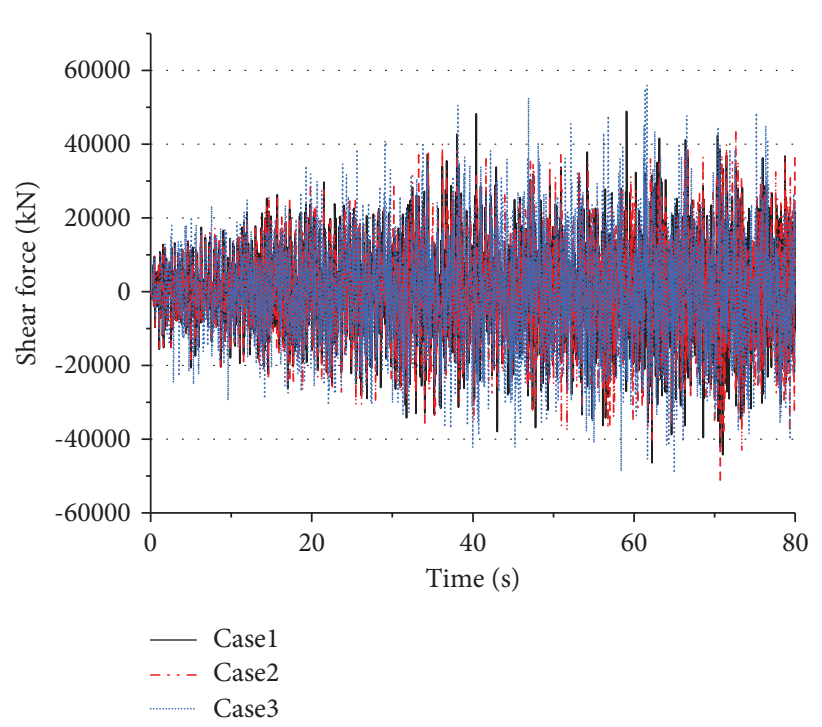

(a)

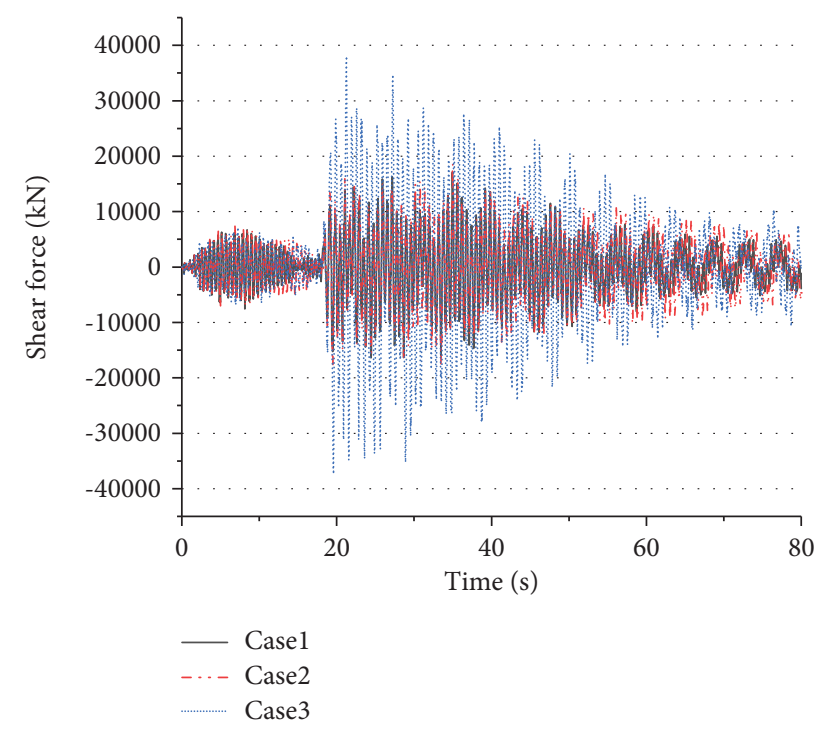

(b)

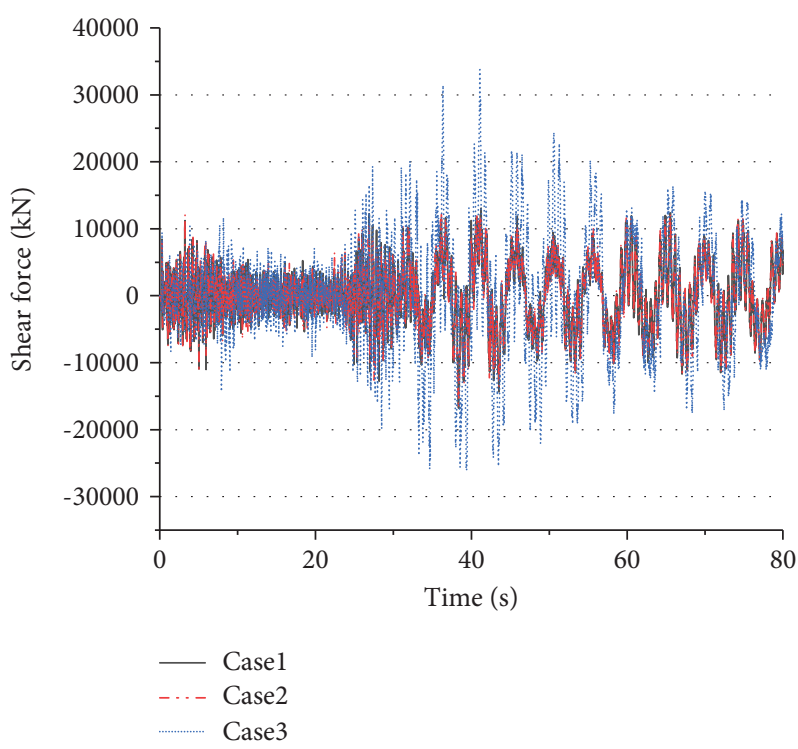

(c)

FIgURE 13: Shear force time history of No. 3 pier in the three earthquakes. (a) 2011-03-11. (b) 2012-03-14. (c) 2019-06-18.

TABLE 6: Maximum bending moment of piers.

\begin{tabular}{|c|c|c|c|c|}
\hline \multirow{2}{*}{ Earthquake event } & \multirow{2}{*}{ Pier number } & \multicolumn{3}{|c|}{ Bending moment $(\mathrm{kN} \cdot \mathrm{m})$} \\
\hline & & Case 1 & Case 2 & Case 3 \\
\hline \multirow{5}{*}{ 2011-03-11 } & 2 & 858,801 & 910,124 & $1,215,150$ \\
\hline & 3 & 806,464 & 844,560 & 978,107 \\
\hline & 4 & 867,296 & 907,327 & $1,280,130$ \\
\hline & 5 & 884,721 & 877,831 & $1,068,080$ \\
\hline & 6 & 912,534 & 925,579 & $1,221,240$ \\
\hline \multirow{5}{*}{ 2012-03-14 } & 2 & 677,307 & 715,792 & $1,201,820$ \\
\hline & 3 & 743,152 & 763,385 & $1,080,640$ \\
\hline & 4 & 644,806 & 729,471 & $1,302,460$ \\
\hline & 5 & 666,342 & 707,164 & $1,128,380$ \\
\hline & 6 & 732,715 & 730,866 & $1,177,980$ \\
\hline
\end{tabular}


TABle 6: Continued.

\begin{tabular}{|c|c|c|c|c|}
\hline \multirow{2}{*}{ Earthquake event } & \multirow{2}{*}{ Pier number } & \multicolumn{3}{|c|}{ Bending moment $(\mathrm{kN} \cdot \mathrm{m})$} \\
\hline & & Case 1 & Case 2 & Case 3 \\
\hline \multirow{5}{*}{ 2019-06-18 } & 2 & 857,825 & 834,244 & $1,062,420$ \\
\hline & 3 & 936,456 & 936,685 & $1,147,420$ \\
\hline & 4 & 918,459 & 905,394 & $1,133,510$ \\
\hline & 5 & 971,546 & 958,216 & $1,119,870$ \\
\hline & 6 & 833,633 & 848,786 & $1,083,430$ \\
\hline
\end{tabular}

TABle 7: Maximum shear force of piers.

\begin{tabular}{|c|c|c|c|c|}
\hline \multirow{2}{*}{ Earthquake event } & \multirow{2}{*}{ Pier number } & \multicolumn{3}{|c|}{ Shear force $(\mathrm{kN})$} \\
\hline & & Case 1 & Case 2 & Case 3 \\
\hline \multirow{5}{*}{ 2011-03-11 } & 2 & 45,950 & 53,104 & 65,986 \\
\hline & 3 & 48,921 & 51,959 & 55,991 \\
\hline & 4 & 50,705 & 52,309 & 62,225 \\
\hline & 5 & 50,131 & 49,201 & 60,051 \\
\hline & 6 & 49,654 & 56,266 & 67,626 \\
\hline \multirow{5}{*}{ 2012-03-14 } & 2 & 17,284 & 15,568 & 45,669 \\
\hline & 3 & 17,113 & 18,508 & 38,040 \\
\hline & 4 & 17,933 & 17,218 & 38,775 \\
\hline & 5 & 15,611 & 16,610 & 40,957 \\
\hline & 6 & 17,298 & 17,838 & 45,971 \\
\hline \multirow{5}{*}{ 2019-06-18 } & 2 & 15,236 & 15,333 & 30,861 \\
\hline & 3 & 16,787 & 16,798 & 33,777 \\
\hline & 4 & 16,792 & 17,299 & 33,779 \\
\hline & 5 & 18,076 & 17,271 & 33,168 \\
\hline & 6 & 13,382 & 13,660 & 31,357 \\
\hline
\end{tabular}

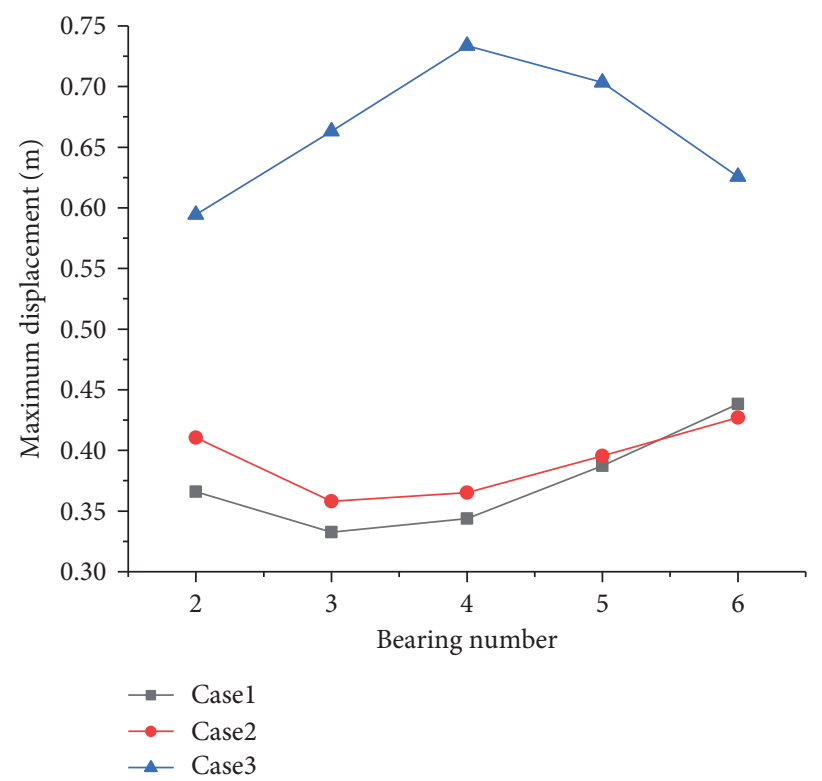

(a)

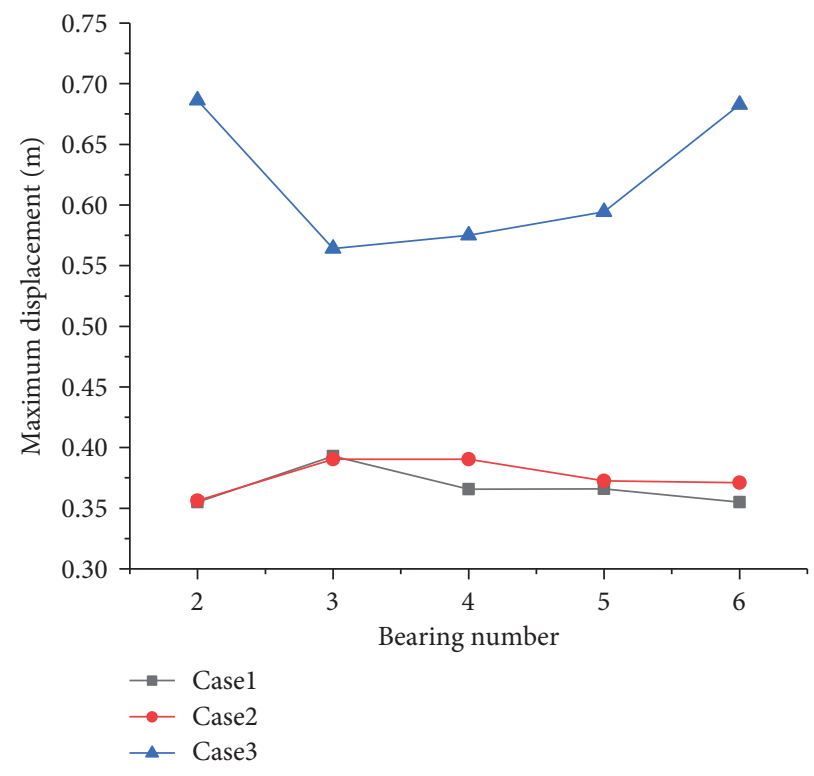

(b)

Figure 14: Continued. 


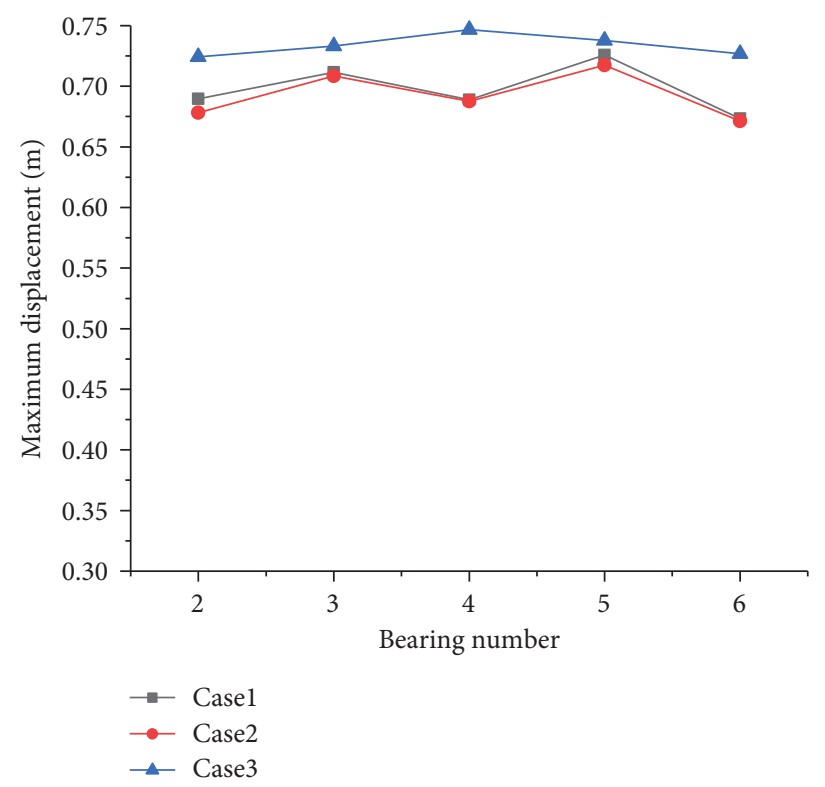

(c)

FIGURE 14: Longitudinal peak displacement of bearings in the three earthquakes. (a) 2011-03-11. (b) 2012-03-14. (c) 2019-06-18.

3.2.3. Bearing Displacement. The maximum displacement of bearings under the action of three earthquakes is shown in Figures $14(\mathrm{a})-14(\mathrm{c})$. It can be seen from these figures that there is no significant difference between the peak displacement of Case 1 and Case 2. In the 2019-06-18 earthquake event, the peak displacement of Case 2 is even smaller than that of Case 1, as shown in Figure 14(c), indicating that the seawater has limited influence on the longitudinal displacement of the bridge bearings. By comparing Case 2 and Case 3 to determine the influence of muddy soil, it is found that the bridge in the muddy soil has a greater seismic response. The longitudinal displacement of No. 4 bearing in Case 3 is 2 times that in Case 2 in the 2011-03-11 earthquake. It can be found from Figure 14(b) that the displacement of bearings of Case 3 increased by $40 \%-90 \%$ compared with Case 2 in the 2012-03-14 earthquake, so the risk of falling of girder is very likely. The amplification effect of the muddy soil on the bearing displacement is the same as that on the internal force of the piers.

\section{Conclusions}

In order to establish an accurate numerical model for seismic response analysis of sea-crossing bridges, the study built a seawater-muddy soil-isolated bridge coupling model including seawater layer and submarine overburdens. To compare By comparing different submarine site models, the influence of seawater and muddy soft-soil layers on the seismic response of the bridge is determined. The research results can provide references for the refined modeling and seismic design of marine structures. The conclusions are as follows:

(1) The seawater layer can amplify the site response on the seabed. The horizontal PGD can be increased by $22 \%-$ $40 \%$ in Case 2 (model only with seawater layer). But the site response is the most remarkable in Case 3, where the submarine site includes both seawater and muddy soft-soil layers. Compared with Case 1, the displacement and acceleration of the seabed position are increased significantly in Case 3. The PGD increased by at least $58 \%$; PGA increased by $34 \%-127 \%$.

(2) The seawater layer can amplify the relative displacement of the piers by $20 \%-40 \%$, but the influence on the internal force of the piers is limited. The muddy soil will not only increase the relative displacement of the piers by $30 \%-80 \%$ but also increase the shear force at the bottom of the piers by more than $100 \%$ and increase the bending moment by 20\%-70\%. Moreover, the displacement and internal force response of the bridge structure under the combined influence of seawater and muddy soil are amplified the most significant, which is very unfavorable to the seismic performance of the bridge and should be paid more attention to in the seismic design.

(3) The effect of seawater on bearing displacement is limited, but the effect of muddy soil is significant. The bearings' displacement of the bridge in muddy soil site increased by $40 \%-100 \%$. Under the combined influence of seawater and muddy soil, the horizontal displacement of the bridge bearings will be amplified by $150 \%$ to that in the land site (Case 1 ). Therefore, in the seismic design of sea-crossing isolated bridges, the influence of the submarine muddy soft-soil and seawater layers on the seismic response of marine structures should be fully considered. In particular, the muddy soft-soil layer has a significant amplification effect on the horizontal seismic response of sea-crossing bridges. 


\section{Data Availability}

The data used to support the findings of this study are available from the corresponding author upon request.

\section{Conflicts of Interest}

The authors declare that they have no conflicts of interest.

\section{Authors' Contributions}

YJ wrote the article. BK developed the methodology. BK and LF reviewed the article. BK and SY were responsible for funding acquisition. BK supervised the study. All the authors have read and agreed to the published version of the manuscript.

\section{Acknowledgments}

This work was supported by the National Natural Science Foundation of China (51868048 and 51908265) and China Earthquake Administration Basic Research Project (2018D18).

\section{References}

[1] B. Xu, K. Wei, S. Qin, and J. Hong, "Experimental study of wave loads on elevated pile cap of pile group foundation for sea-crossing bridges," Ocean Engineering, vol. 197, Article ID 106896, 2020.

[2] A. Guo, Q. Fang, X. Bai, and H. Li, "Hydrodynamic experiment of the wave force acting on the superstructures of coastal bridges," Journal of Bridge Engineering, vol. 20, no. 12, Article ID 04015012, 2015.

[3] J. Zhang, B. Zhu, A. Kang, R. Yin, X. Li, and B. Huang, "Experimental and numerical investigation of wave-current forces on coastal bridge superstructures with box girders," Advances in Structural Engineering, vol. 23, no. 7, pp. 1438$1453,2020$.

[4] K. Qu, H. S. Tang, A. Agrawal, Y. Cai, and C. B. Jiang, "Numerical investigation of hydrodynamic load on bridge deck under joint action of solitary wave and current," Applied Ocean Research, vol. 75, pp. 100-116, 2018.

[5] L.-Y. Xu, C.-X. Song, W.-Y. Chen, F. Cai, Y.-Y. Li, and G.-X. Chen, "Liquefaction-induced settlement of the pile group under vertical and horizontal ground motions," Soil Dynamics and Earthquake Engineering, vol. 144, Article ID 106709, 2021.

[6] B. Huang, B. Zhu, S. Cui, L. Duan, and Z. Cai, "Influence of current velocity on wave-current forces on coastal bridge decks with box girders," Journal of Bridge Engineering, vol. 23, no. 12, Article ID 04018092, 2018.

[7] Z. X. Li and X. Huang, "Dynamic responses of bridges in deep water under combined earthquake and wave actions," China Civil Engineering Journal, vol. 45, no. 11, pp. 134-140, 2012, in Chinese.

[8] Z. Lin and W. C. Yuan, "Seismic response of bridge pier in deep water considering wave action," Journal of Civil Engineering and Management, vol. 32, no. 2, pp. 37-41, 2015, in Chinese.

[9] W. G. Yuan and M. Y. Liu, "Load effect analysis of cross-sea bridge's pier on the wave and earthquake effect," Journal of
Wuhan University of Technology, vol. 35, no. 12, pp. 120-124, 2013, in Chinese.

[10] Y. Ding, S. B. Meng, and Y. D. Shi, "Stochastic dynamic response analysis of bridge piers in deep water under combined earthquake and wave actions," in Proceedings of the 16th World Conference on Earthquake Engineering, Santiago, Chile, January 2017.

[11] C.-G. Liu and G.-S. Sun, "Calculation and experiment for dynamic response of bridge in deep water under seismic excitation," China Ocean Engineering, vol. 28, no. 4, pp. 445-456, 2014.

[12] Y. Ding, R. Ma, Y.-D. Shi, and Z.-X. Li, "Underwater shaking table tests on bridge pier under combined earthquake and wave-current action," Marine Structures, vol. 58, pp. 301-320, 2018.

[13] P. Wang, M. Zhao, X. Du, and J. Liu, "Dynamic response of bridge pier under combined earthquake and wave-current action," Journal of Bridge Engineering, vol. 24, no. 10, Article ID 04019095, 2019.

[14] H. Jiang, X. Y. Bai, L. Huang, C. Li, X. F. Meng, and Q. S. Yang, "Seismic response characteristics of deep-water piers of seacrossing bridges in wave-current environment," Journal of the China Railway Society, vol. 41, no. 3, pp. 117-127, 2019, in Chinese.

[15] A. J. Wu and W. L. Yang, "Numerical study of pile group effect on the hydrodynamic force on a pile of sea-crossing bridges during earthquakes," Ocean Engineering, vol. 199, Article ID 106999, 2020.

[16] A. J. Wu, W. L. Yang, and L. Zhao, "Influence of wave-current interaction on seismic response of deep-water bridge," World Bridges, vol. 46, no. 4, pp. 73-77, 2018.

[17] H. N. Li, Y. Zhang, and G. Li, "Nonlinear seismic analysis of offshore bridges considering chloride ions corrosion effect," China Civil Engineering Journal, vol. 48, no. 7, pp. 112-122, 2015.

[18] H. Cheng, D.-S. Wang, H.-N. Li, Y. Zou, and K.-N. Zhu, "Investigation on ultimate lateral displacements of coastal bridge piers with different corrosion levels along height," Journal of Bridge Engineering, vol. 26, no. 4, Article ID 04021015, 2021.

[19] S.-C. Wang, K.-Y. Liu, C.-H. Chen, and K.-C. Chang, "Experimental investigation on seismic behavior of scoured bridge pier with pile foundation," Earthquake Engineering \& Structural Dynamics, vol. 44, no. 6, pp. 849-864, 2015.

[20] C. Liu, S. Zhang, and E. Hao, "Joint earthquake, wave and current action on the pile group cable-stayed bridge tower foundation: an experimental study," Applied Ocean Research, vol. 63, pp. 157-169, 2017.

[21] H. Diao, J. Hu, and L. Xie, "Effect of seawater on incident plane $\mathrm{P}$ and $\mathrm{SV}$ waves at ocean bottom and engineering characteristics of offshore ground motion records off the coast of southern California, USA," Earthquake Engineering and Engineering Vibration, vol. 13, no. 2, pp. 181-194, 2014.

[22] D. M. Boore and C. E. Smith, "Analysis of earthquake recordings obtained from the seafloor earthquake measurement system (SEMS) instruments deployed off the coast of southern California," Bulletin of the Seismological Society of America, vol. 89, no. 1, pp. 260-274, 1999.

[23] C. Li, H. Hao, H. Li, and K. Bi, "Theoretical modeling and numerical simulation of seismic motions at seafloor," Soil Dynamics and Earthquake Engineering, vol. 77, pp. 220-225, 2015.

[24] Y. P. Dhakal, S. Aoi, T. Kunugi, W. Suzuki, and T. Kimura, "Assessment of nonlinear site response at ocean bottom 
seismograph sites based on s-wave horizontal-to-vertical spectral ratios: a study at the Sagami bay area K-NET sites in Japan," Earth Planets and Space, vol. 69, no. 29, pp. 1-7, 2017.

[25] B. K. Chen, D. S. Wang, H. N. Li, Z. G. Sun, and Y. Shi, "Characteristics of earthquake ground motion on the seafloor," Journal of Earthquake Engineering, vol. 19, no. 9, pp. 874-904, 2015.

[26] B. Chen, D. Wang, S. Chen, and S. Hu, "Influence of site factors on offshore ground motions: observed results and numerical simulation," Soil Dynamics and Earthquake Engineering, vol. 145, Article ID 106729, 2021.

[27] B. B. Soneji and R. S. Jangid, "Influence of soil-structure interaction on the response of seismically isolated cablestayed bridge," Soil Dynamics and Earthquake Engineering, vol. 28, no. 4, pp. 245-257, 2008.

[28] S. Li, F. Zhang, J.-q. Wang, M. S. Alam, and J. Zhang, "Seismic responses of super-span cable-stayed bridges induced by ground motions in different sites relative to fault rupture considering soil-structure interaction," Soil Dynamics and Earthquake Engineering, vol. 101, pp. 295-310, 2017.

[29] C. Li, H.-N. Li, H. Hao, K. Bi, and B. Chen, "Seismic fragility analyses of sea-crossing cable-stayed bridges subjected to multi-support ground motions on offshore sites," Engineering Structures, vol. 165, pp. 441-456, 2018.

[30] E. N. Tochaei, T. Taylor, and F. Ansari, "Effects of near-field ground motions and soil-structure interaction on dynamic response of a cable-stayed bridge," Soil Dynamics and Earthquake Engineering, vol. 133, Article ID 106115, 2020.

[31] L. Sun and W. Xie, "Evaluation of pile-soil-structure interaction effects on the seismic responses of a super long-span cable-stayed bridge in the transverse direction: a shaking table investigation," Soil Dynamics and Earthquake Engineering, vol. 125, Article ID 105755, 2019.

[32] K. Bi, H. Hao, and N. Chouw, "Influence of ground motion spatial variation, site condition and SSI on the required separation distances of bridge structures to avoid seismic pounding," Earthquake Engineering \& Structural Dynamics, vol. 40, no. 9, pp. 1027-1043, 2011.

[33] Z. W. Chen, Q. H. Pu, H. Y. Jia, X. Li, and Y. X. Huang, "Analysis of seismic response of high pier and long-span railway bridge based on site effect," World Earthquake Engineering, vol. 32, no. 2, pp. 82-88, 2016, in Chinese.

[34] K. Bathe, ADINA: Theory and Modeling Guide Volume I: ADINA Solids \& Structures, ADINA R\&D, Watertown, MA, USA, 2016.

[35] F. C. Meng, M. H. Liu, W. S. Wu, G. J. Zhang, and L. Zhang, "The design philosophy and bridge's technical innovation of Hong Kong-Zhuhai-Macau bridge," Engineering Sciences, vol. 17, no. 1, pp. 27-35+41, 2015, in Chinese.

[36] X. L. Mei and Z. Q. Zhang, "Analysis of installation geometric shapes of steel box girder of non-navigable span bridge of Hong Kong-Zhuhai-Macao bridge over deep water area," Bridge Construction, vol. 46, no. 1, pp. 106-110, 2016, in Chinese.

[37] X. M. Meng, "Lead isolation rubber bearing construction technology discussion," Transportation Science \& Technology, no. 2, pp. 28-31, 2014, in Chinese.

[38] S. Z. Ma, Y. B. Chen, and T. H. Chen, "Engineering geological features of the bridge of Guangdong and Hong Kong and Macao," Geological Research of South China Sea, pp. 156-164, 2006, in Chinese.

[39] Z. J. Xiao, T. J. Li, and S. Z. Liao, "Surface sediment characteristics and transport trend in Lingdingyang bay of the
Pearl river estuary," Journal of Tropical Oceanography, vol. 30, no. 4, pp. 58-65, 2011, in Chinese.

[40] B. K. Chen, Characteristics of Offshore Ground Motions and Seismic Response Analysis of Sea-Crossing Bridges, Dalian University of Technology, Dalian, China, 2016.

[41] J. Yang and T. Sato, "Interpretation of seismic vertical amplification observed at an array site," Bulletin of the Seismological Society of America, vol. 90, no. 2, pp. 275-285, 2000.

[42] J. Yang and T. Sato, "Influence of viscous coupling on seismic reflection and transmission in saturated porous media," Bulletin of the Seismological Society of America, vol. 88, no. 5, pp. 1289-1299, 1998.

[43] J. B. Liu, Y. Gu, and Y. X. Du, "Consistent viscous-spring artificial boundaries and viscous-spring boundary elements," Chinese Journal of Geotechnical Engineering, vol. 9, pp. 1070-1075, 2006, in Chinese.

[44] J. B. Liu and B. Li, "A unified viscous-spring artificial boundary for 3-d static and dynamic applications," Science in China Series E Engineering and Materials Science, vol. 35, no. 9, pp. 966-980, 2005, in Chinese.

[45] B. K. Chen, D. S. Wang, and H. Cheng, "Research review on the application of viscous-spring artificial boundary in earthquake engineering," Journal of Seismological Research, vol. 39, no. 1, pp. 137-142+182, 2016, in Chinese.

[46] Y. Gu, J. B. Liu, and Y. X. Du, “3D Consistent viscous-spring artificial boundary and viscous-spring artificial boundary element," Engineering Mechanics, vol. 24, no. 12, pp. 31-37, 2007, in Chinese. 